\title{
Proximal anal sinus resection as an alternative to fistulectomy and seton for reducing recurrence of anal fistulas: a retrospective study
}

\author{
Chao Lei”, Chao Li", Min Liu, Zhen Song, Chen Li, Zhihua Liu^^ \\ Department of Anorectal Surgery, the Fifth Affiliated Hospital of Guangzhou Medical University, Guangzhou, China \\ Contributions: (I) Conception and design: Z Liu; (II) Administrative support: None; (III) Provision of study materials or patients: None; (IV) \\ Collection and assembly of data: C Lei, Chao Li, M Liu, Chen Li, Z Liu; (V) Data analysis and interpretation: C Lei, Chao Li; (VI) Manuscript \\ writing: All authors; (VII) Final approval of manuscript: All authors. \\ "These authors contributed equally to this work. \\ Correspondence to: Zhihua Liu. Department of Anorectal Surgery, the Fifth Affiliated Hospital of Guangzhou Medical University, 621 Gangwan Road, \\ Guangzhou, Guangdong 510799, China. Email: liuzhihualzh@hotmail.com.
}

Background The recurrence rate of anal fistula following classic surgery is a common issue. The purpose
of the present study was to compare the recurrence rate of anal fistula following classic surgery (fistulectomy
or seton) and proximal anal sinus resection (PASR) in a cohort study.

Methods: From May 2016 to May 2018, 106 patients who did the anal fistula surgery (classic or PASR) were studied with 2 groups; 74 patients were allocated to the classic surgery group and 32 patients were allocated to the PASR group. Fifty-two patients were excluded because they did not meet the inclusion criteria. We analyzed the recurrence rate of anal fistula, wound healing time, surgical complications, and duration of pain.

Results: Patient characteristics, grouped by surgical approach, showed no significant difference. There was a significant difference in the recurrence rate between the classic surgery group and the PASR group (16.2\% vs. $0 \%, \mathrm{P}<0.05)$. There was no significant difference in the surgical complications in the 2 groups $(\mathrm{P}>0.05)$. The mean healing time in the 2 groups was not significantly different; 41.6 days in the classic group $(\mathrm{P}>0.05)$ and 40.8 days in the PASR group. Our results also found no significant difference in the duration of pain between the 2 groups; $5.1 \pm 1.5$ days in the classic group and 5.0 \pm 1.0 days in the PASR group (P>0.05).

Conclusions: PASR was found to have a lower recurrence rate of anal fistula and did not increase the risk of complications. Therefore, PASR should be considered as a first line of treatment for patients at risk of anal fistula recurrence.

Keywords: Fistula; operation; recurrence; anal sinus; proximal anal sinus resection (PASR)

Submitted Sep 28, 2021. Accepted for publication Nov 17, 2021.

doi: 10.21037/apm-21-3127

View this article at: https://dx.doi.org/10.21037/apm-21-3127

\section{Introduction}

Anal fistula is caused by infected anal glands (1). As a common disease, it needs surgical treatment. According to a previous report, the incidence of anal fistula in European ranges from $0.01 \%$ to $0.02 \%$ (1). Most anal fistulas are secondary to perianal abscesses and form an invisible fistula that connects the anorectal mucosa and the perianal skin. In general, anal fistula will not heal spontaneously; most need to be treated with surgery. The propose of surgery is to

\footnotetext{
^ ORCID: 0000-0001-5784-9724.
} 
eliminate local pyemia, promote fistula healing, and protect the function of sphincter contraction (2).

The most common operations performed for anal fistulas are fistulotomy and fistulectomy and seton therapy. Surgical treatment of a fistula-in-ano is associated with a significant risk of recurrence (3). In a previously published meta-analysis, the recurrence rate of anal fistula after operation was found to be between $10 \%$ and $57 \%$ (4). In another study, the 3 -year recurrence rate of low anal fistula treated with fistulotomy was 7\% (5), and in Jordán et al.'s study of 279 patients who had undergone anal fistula surgery, recurrence occurred in $7.2 \%$ patients (6). In a large-scale, multicenter study of 537 patients with low anal fistula who underwent fistulotomy, 88 (16.4\%) developed recurrence following surgery (7). Compared with other anal fistula operations, fistulectomy was found to have the lowest postoperative recurrence rate, as anal fistulectomy is relatively safe, simple, and widely used in surgery (8). However, anal fistulectomy is only suitable for simple low anal fistula, and the application of fistulectomy for complex anal fistula is limited. Other surgical methods, such as anal plug, have been proposed in recent years (8). The recurrence rate of anal fistula following anal plug ranges from $27 \%$ to $84 \%(9,10)$. Although the fistulectomy or seton as the surgical approach was used widely in the treatment of anal fistula, the recurrence rate is still high, and fistula recurrence could lead to even more difficulties to deal with.

Surprisingly, anal gland infection is considered to be one of the most common causes of anal fistula (11). There are 8-12 glands located between, outside, or inside the sphincter, opening to the dentate line and looped around. When those glands are infected, it can subsequently cause fistulas. It is hypothesized that the infection of anal glands is the main cause of the postoperative recurrence of anal fistulas (11). One study discussed the use of video-assisted anal fistula treatment (VAAFT) fistuloscope in the treatment of chronic sinus tracts (12). And this technique mainly used for the treatment of anastomotic leakage following low anterior resection (12). However, a controlled study may be needed to prove its effects on anal fistula. The proximal anal sinus tends to be infected in fistula patients; therefore, the purpose of this retrospective study was to explore whether resection of anal glands around the anal fistula could reduce the recurrence rate of anal fistula following surgery. The anorectal surgery team of the Fifth Affiliated Hospital of Guangzhou Medical University participated in the trial and proposed a new surgical approach: proximal anal sinus resection (PASR). The main step of PASR is to remove the potential inner opening (the possible infected anal gland) and the 2 other antral sinuses nearby. Although we have invented the PASR for a few years, the application has not been widely performed in clinical. The aim of the present study was to compare the recurrence rate of anal fistula between classic surgery (fistulectomy or seton) and PASR, and to determine the effects of PASR on anal fistula. We retrospectively analyzed 106 patients who had undergone classic surgery or PASR. Our findings indicate that PASR is a suitable alternative to fistulectomy and seton for reducing the recurrence of anal fistula. We present the following article in accordance with the STROBE reporting checklist (available at https://dx.doi.org/10.21037/apm-21-3127).

\section{Methods}

\section{Patients}

From May 2016 to May 2018, 158 patients with anal fistula who suffered from the surgery were selected for study, 52 patients were excluded because they did not meet the inclusion criteria. According to the record of the operation, 74 patients suffered from the classic surgery, while 32 patients suffered from the PASR treatment. Therefore, we divided the patients into 2 groups according to the surgical approach. Age and sex differences between the 2 groups were not statistically significant $(\mathrm{P}>0.05)$, as shown in Table 1 .

\section{Ethical statement}

The study was approved by the Ethics Committee of the Fifth Affiliated Hospital of Guangzhou Medical University (No.: 2016012). The study was conducted in accordance with the Declaration of Helsinki (as revised in 2013). All participants have provided signed informed consent prior to participating.

\section{Inclusion and exclusion criteria}

The inclusion criteria were as follows: (I) anal fistula was confirmed by clinical examination and diagnosed as the low position of the fistula; (II) there was no contraindication of surgery for those patients; (III) it was the first time patients developed anal fistula; and the exclusion criteria were as follows: (I) patients who had colorectal cancer, mental illness, or diabetes, and any related other diseases; (II) pregnant or lactating patients; (III) patients acute inflammatory reaction of other position of the body; and (IV) patients with inflammatory bowel disease. 


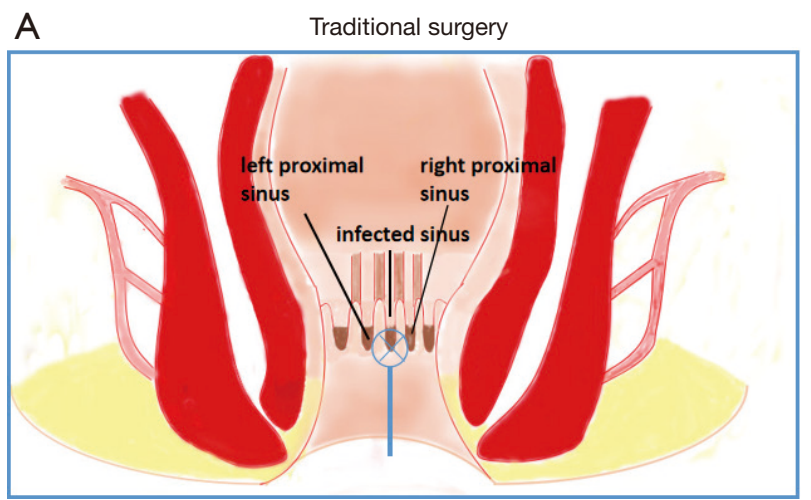

B

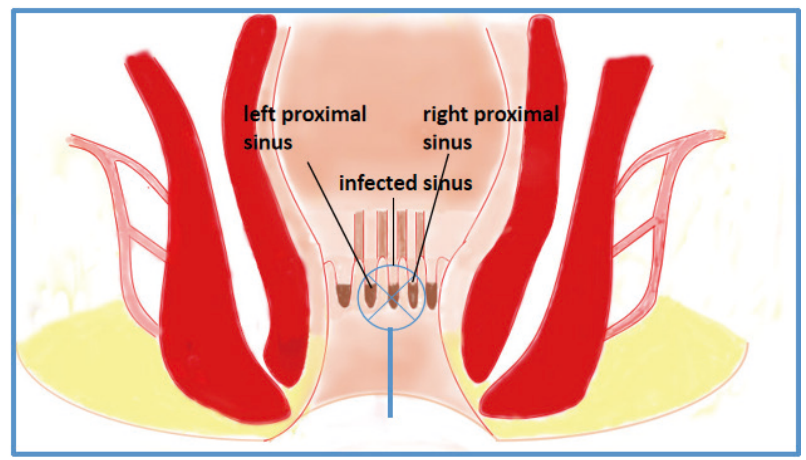

Figure 1 The comparison of the new surgical approach PASR and the classic surgery. (A) Classic surgery (fistulectomy and seton therapy) and proximal anal sinus resection for all 3 antral sinuses. (B) Classic surgery. Only the most relevant antral sinuses were resected. PASR, proximal anal sinus resection.

\section{Operation type}

\section{Fistulectomy}

First, we tried to find and confirm the external anal fistula opening and injected $1 \%$ methylene blue into the fistula via the opening. The surgeon then inserted their index finger into the patient's rectum as a guide. The fistula was explored from the external opening by blunt probe. The blunt probe went through the whole fistula to confirm the inner opening. Next, we cut and opened the fistula. An electrotome was used to cut along the periphery of the fistula to remove the fistula.

\section{Seton}

The fistula was explored from the external opening by a blunt probe. The blunt probe went through the whole fistula, then came out from the inner opening. The rubber band passed the whole fistula following the movement of blunt probe. We then cut and opened the skin and subcutaneous tissue located between the external and inner opening of the fistula before performed seton therapy.

\section{PASR}

Based on the above 2 surgeries, Alice tissue forceps and anoscope were used to expose the inner opening (the primary antral sinus and 2 other antral sinuses that were located at both sides). An electric knife was then used to remove all 3 antral sinuses. The approximate position is shown in Figure 1.

\section{Postoperative care}

After routine postoperative lying for 4-6 h, the diet was changed to normal. If the patients had difficulty urinating, a urine tube was used. First-generation cephalosporin was used for 1 day. Topical application of analgesic and antiswelling drugs was required for 2 weeks, and sitting bath for 4-6 weeks. Patients were advised to avoid heavy physical work for 2 weeks.

\section{Follow-up}

After discharge from the hospital, patients were followed up and monitored for healing, complications, and recurrence. Clinical healing was defined as complete closure of the internal opening and the external wound, with no symptoms of inflammation. Healing is not usually checked with ultrasound or magnetic resonance imaging. Recurrence was defined as the reappearance of a fistula. Follow-up appointments were scheduled in the second week after surgery, unless required sooner, and were dependent on patients' symptoms. Patients attended the clinic 1-2 times per week until the wound healed. Telephone interviews were performed at 6 weeks, 3 months, 6 months and 1 year postoperatively. After 1 year, we recognize no recurrence of patients unless they informed us some aberrant situations.

\section{Statistical analysis}

A sample-size calculation based on the published prevalence of normal surgical approach demonstrated that 32 patients would be required in each group to demonstrate a reduction in recurrence from $20 \%$ to $5 \%$ at the $5 \%$ significance level. Statistical analysis was performed using SPSS 19.0 (Inc., Chicago, IL, USA). Student's $t$-test was used to 
Table 1 Patient characteristics grouped by surgical operation

\begin{tabular}{|c|c|c|c|}
\hline Surgical type & $\begin{array}{l}\text { Classic surgery } \\
\qquad(n=74)\end{array}$ & $\begin{array}{l}\text { PASR } \\
(n=32)\end{array}$ & $P$ \\
\hline Age, years & $35.4 \pm 9.3$ & $35.0 \pm 9.0$ & $0.26^{a}$ \\
\hline Male/female & $68 / 6$ & $30 / 2$ & $1.00^{\circ}$ \\
\hline BMI, $\mathrm{kg} / \mathrm{m}^{2}$ & $24.6 \pm 3.0$ & $24.7 \pm 2.8$ & $0.57^{\mathrm{a}}$ \\
\hline Smoking (\%) & $16(21.6)$ & $10(31.2)$ & $0.29^{b}$ \\
\hline Alcohol consumption (\%) & $7(9.5)$ & $4(12.5)$ & $0.38^{b}$ \\
\hline \multicolumn{4}{|l|}{ Comorbidities, $\mathrm{n}$} \\
\hline Diabetes mellitus & 0 & 0 & 0 \\
\hline Crohn's disease & 0 & 0 & 0 \\
\hline Tuberculosis & 0 & 0 & 0 \\
\hline Hypertension & 0 & 0 & 0 \\
\hline Types of fistula & & & $0.59^{b}$ \\
\hline Simple fistula & 59 & 24 & \\
\hline Complex fistula & 15 & 8 & \\
\hline \multicolumn{4}{|l|}{ Park's classification } \\
\hline Perirectal fistula & 12 & 5 & \\
\hline Intersphincteric fistula & 36 & 18 & \\
\hline Transsphincteric & 16 & 6 & \\
\hline Extrasphincteric fistula & 10 & 3 & \\
\hline Types of operation, $n$ & & & $0.00^{b}$ \\
\hline Fistulectomy & 33 & 14 & \\
\hline Seton & 41 & 18 & \\
\hline
\end{tabular}

${ }^{\mathrm{a}}, t$-test; ${ }^{\mathrm{b}}$, Chi-square analysis; ${ }^{\mathrm{c}}$, continuity correction chi-square analysis.

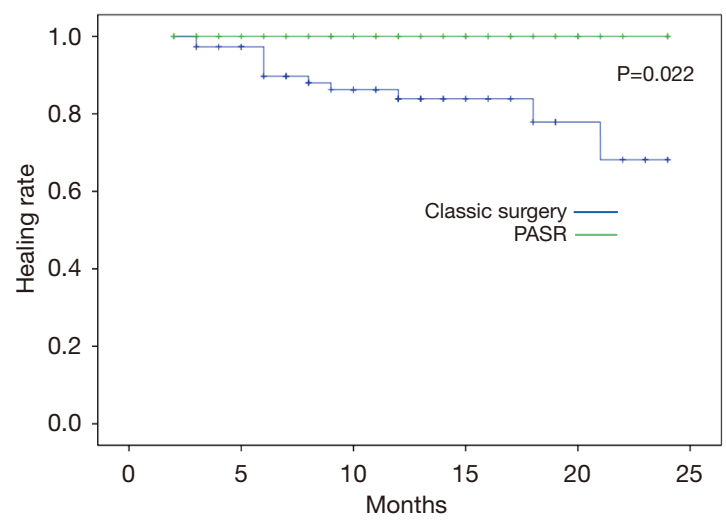

Figure 2 Kaplan-Meier curves showing the healing rate between the 2 groups $(\mathrm{P}=0.022)$. compare continuous variables, and Fisher's exact test was used for proportion comparison. Survival analysis was used to compare the time of recurrence in the 2 groups. Subgroup analysis was not used in the present study. Mean substitution was used for missing data. All $\mathrm{P}$ values were 2 sided and considered statistically significant when $\mathrm{P} \leq 0.05$.

\section{Results}

In the present study, 106 patients with anal fistula were selected and divided into 2 groups; 74 patients were allocated to the classic surgery group and 32 patients were allocated to the PASR group. Fifty-two patients were excluded because they did not meet the inclusion criteria. Patient characteristics, grouped by surgical approach, showed no significant difference (Table 1). Two patients had missing data for healing time, and 5 had missing data for duration of pain.

We compared the differences between the classic surgery group and the PASR group, and found a significant difference in the recurrence rate $(16.2 \%$ vs. $0 \%)$ during the follow-up period $(\mathrm{P}<0.05)$. In the classic surgery group, 2 patients developed recurrence after 3 months, 1 patient developed recurrence after 5 months, 6 patients developed recurrence after 6 months, 1 patient developed recurrence after 8 months, and 2 patients developed recurrence after 12 months (Figure 2). In the classic surgery group, the wounds of 2 patients swelled while in hospital and another 3 patients had a small amount of exuded liquid from the surgical incision, accompanied by pain following discharge. In the PASR group, there were 4 patients who had a little amount of exuded liquid from the surgical incision accompanied by pain following discharge. The mean healing time in the 2 groups was not significantly different; 41.6 days in the classic group $(\mathrm{P}>0.05)$ and 40.8 days in the PASR group. Our results found no significant difference in the duration of pain between the 2 groups; $5.1 \pm 1.5$ days in the classic group and 5.0 \pm 1.0 days in the PASR group $(\mathrm{P}>0.05)$ (Table 2).

\section{Discussion}

In a previously published study of 279 patients who had undergone anal fistula surgery, Jordán et al. reported that the factors of recurrence included the type of fistula (extrasphincteric/suprasphincteric), non-discovery of the internal opening, complex fistulas, and associated chronic abscesses. However, only complex fistulas and 
Table 2 Outcomes of the two surgical approaches

\begin{tabular}{|c|c|c|c|}
\hline Surgical type & $\begin{array}{l}\text { Classic surgery } \\
\qquad(\mathrm{n}=74)\end{array}$ & $\begin{array}{l}\text { PASR } \\
(n=32)\end{array}$ & $P$ \\
\hline Healing time (day) & $41.6 \pm 10.2$ & $40.8 \pm 14$ & $0.05^{\mathrm{a}}$ \\
\hline Duration of pain (day) & $5.1 \pm 1.5$ & $5.0 \pm 1.0$ & $0.59^{\mathrm{a}}$ \\
\hline Recurrence rate, $\mathrm{n}(\%)$ & $12(16.2)$ & $0(0)$ & $0.04^{\mathrm{C}}$ \\
\hline \multicolumn{4}{|l|}{ Postoperative complications, $\mathrm{n}$} \\
\hline Wound bleeding & 0 & 0 & \\
\hline Anal fissure & 0 & 0 & \\
\hline Persistent pain & 0 & 0 & \\
\hline Wound infection & 3 & 4 & \\
\hline Mean follow-up period, month & $14.3 \pm 5.5$ & $14.7 \pm 5.9$ & $0.39^{\mathrm{a}}$ \\
\hline
\end{tabular}

non-discovery of the internal opening were statistically significant in the multivariate analysis (6). In a retrospective cohort study of 251 patients with high trans-sphincteric fistulas who were treated with seton placement, factors that led to recurrence included previous fistula surgery, anterior anal fistulas, the presence of secondary tracks or branches as supralevator extension, and horseshoe fistulas (13). New surgical procedures have emerged in recent years, such as ligation of the intersphincteric fistula tract (LIFT), which has been reported as having satisfactory results in short- and long-term follow-up, with a low risk of complications (14). However complex and recurrent fistulas seem to be risk factors of LIFT failure (14). Stem cell therapy has been used to resolve very complex anal fistula, and 10 patients with highly recurrent and complex fistulas were treated with stem cell therapy in a previously published study; 1 year later, 6 patients $(60 \%)$ did not develop recurrence, and it seems the recurrence rate is still high (15).

According to our experience in treating recurrent fistula, the causes of recurrent anal fistula can be divided into the following situations: (I) the preoperative diagnosis is insufficient; the doctor only checks the anorectal location without noticing complications, such as tuberculosis, Crohn's disease, diabetes, and other systemic diseases. It is worth noting that anal fistulas are a common manifestation of Crohn's disease (16); (II) the fistula is not properly evaluated, which results in inaccurate incision and drainage; (III) the inner opening is the key step of the surgical treatment of fistula. When the inner opening is not fully cut apart, this will lead to poor postoperative healing; and
(IV) both ends of the fistula incision are easy to close. The surrounding skin grows together; however, the fistula cavity is not fully filled by granulation tissue; this is known as the pseudo healing. Some potential source of infection may cause recurrence of anal fistula; therefore, it is important to inspect the inner opening carefully to prevent recurrence.

Our results showed that the recurrence rate of anal fistula following classic surgery plus PASR was lower when compared with classic surgery alone. To the best of our knowledge, this is the first report to use the new PASR operation for improving the efficacy of anal fistula surgical treatment based on classic surgery. Interestingly, there was no recurrence in patients who had undergone PASR at the 1-year follow-up compared with 12 patients with recurrence in the classic surgery control group within the same timeframe. The outcomes indicated the apparent relationship between the proximal anal sinuses and the recurrence of anal fistula, and the potential role of PASR in preventing recurrence.

The PASR needed to cut off the 2 adjacent anal sinuses which lead to a bigger injury, but our results revealed that the complications, which included the duration of pain and wound healing, did not show a significant difference, which suggested that this advanced operation did not impact the recovery of surgery treatment. During the follow-up period, none of the patients presented with complications, such as anal strictures, which indicated that external excision does not increase the risk of serious complications.

Seton therapy is a classic surgery for anal fistula that is used worldwide. It is safe for incontinence, as the seton stimulates the contact segment continuously, which keeps the anal sphincter conjoint (17). However, the wound heals slowly and the recurrence rate is not optimistic. Fistulectomy has a lower recurrence rate than seton because the infectious tissue of the fistula was removed completely, but the risk of incontinence increased because of the injury of sphincter (8). The new surgical approach should improve therapeutic efficacy to reduce the recurrence rate of anal fistula without impacting other evaluation indexes. Anal fistulas are complex, therefore, advanced surgical procedures are continuously researched. When considering the advantages and disadvantages of classic surgery, as well as the main factors influencing surgical efficacy, we designed the PASR based on classic surgery. However, the present study was limited by its small samples and its retrospective study method. To further confirm the effect of PASR, large sample sizes and randomized controlled trials are warranted. Furthermore, because the surgical approach 
is a bit complicated, the operation time is longer than the classic fistulectomy or seton approach. And the newer doctors should be trained for the new surgery to achieve the ideal therapeutic effects. Our results confirmed that PASR can be adapted for recurrent or persistent anal fistulas. Our research provides key evidence for anal glands as the potential source of recurrence and provides a new way to reduce the recurrence rate of anal fistula.

\section{Conclusions}

Classic surgery plus PASR significantly reduces the recurrence rate of anal fistula. Advanced surgical procedures do not increase the risk of surgical complications nor prolong the duration pain and wound healing. PASR can be considered an effective therapeutic target to reduce the recurrence rate of anal fistula and as a first line of treatment for patients with recurrent anal fistulas.

\section{Acknowledgments}

Funding: This work was financially supported by the National Natural Science Foundation of China (No.: 81670480), the Guangzhou Science and Technology Plan Joint Foundation of City and University (No.: 202102010085), the Major Scientific Research Projects at Provincial Level in Guangdong General University (No.: 2017KZDXM068), and the Innovation Team Project of Guangzhou Education Bureau (No.: 201831828).

\section{Footnote}

Reporting Checklist: The authors have completed the STROBE reporting checklist. Available at https://dx.doi. org/10.21037/apm-21-3127

Data Sharing Statement: Available at https://dx.doi. org/10.21037/apm-21-3127

Conflicts of Interest: All authors have completed the ICMJE uniform disclosure form (available at https://dx.doi. org/10.21037/apm-21-3127). The authors report that this work was financially supported by the National Natural Science Foundation of China (No.: 81670480), the Guangzhou Science and Technology Plan Joint Foundation of City and University (No.: 202102010085), the Major Scientific Research Projects at Provincial Level in Guangdong General University (No.: 2017KZDXM068), and the Innovation Team Project of Guangzhou Education Bureau (No.: 201831828). The authors have no other conflicts of interest to declare.

Ethical Statement: The authors are accountable for all aspects of the work in ensuring that questions related to the accuracy or integrity of any part of the work are appropriately investigated and resolved. The study was approved by the Ethics Committee of the Fifth Affiliated Hospital of Guangzhou Medical University (No.: 2016012). The study was conducted in accordance with the Declaration of Helsinki (as revised in 2013). All participants have provided signed informed consent prior to participating.

Open Access Statement: This is an Open Access article distributed in accordance with the Creative Commons Attribution-NonCommercial-NoDerivs 4.0 International License (CC BY-NC-ND 4.0), which permits the noncommercial replication and distribution of the article with the strict proviso that no changes or edits are made and the original work is properly cited (including links to both the formal publication through the relevant DOI and the license). See: https://creativecommons.org/licenses/by-nc-nd/4.0/.

\section{References}

1. Zanotti C, Martinez-Puente C, Pascual I, et al. An assessment of the incidence of fistula-in-ano in four countries of the European Union. Int J Colorectal Dis 2007;22:1459-62.

2. Limura E, Giordano P. Modern management of anal fistula. World J Gastroenterol 2015;21:12-20.

3. Zhang Y, Li F, Zhao T, et al. Efficacy of video-assisted anal fistula treatment combined with closure of the internal opening using a stapler for Parks II anal fistula. Ann Transl Med 2020;8:1517.

4. Jacob TJ, Perakath B, Keighley MR. Surgical intervention for anorectal fistula. Cochrane Database Syst Rev 2010;(5):CD006319.

5. Zimmerman DD, Mitalas LE, Schouten WR. Long-term functional outcome and risk factors for recurrence after surgical treatment for low and high perianal fistulas of cryptoglandular origin. Dis Colon Rectum 2009;52:11967; author reply 1197.

6. Jordán J, Roig JV, García-Armengol J, et al. Risk factors for recurrence and incontinence after anal fistula surgery. Colorectal Dis 2010;12:254-60. 
7. Göttgens KW, Janssen PT, Heemskerk J, et al. Long-term outcome of low perianal fistulas treated by fistulotomy: a multicenter study. Int J Colorectal Dis 2015;30:213-9.

8. Wang Q, He Y, Shen J. The best surgical strategy for anal fistula based on a network meta-analysis. Oncotarget 2017;8:99075-84.

9. de la Portilla F, Rada R, Jiménez-Rodríguez R, et al. Evaluation of a new synthetic plug in the treatment of anal fistulas: results of a pilot study. Dis Colon Rectum 2011;54:1419-22.

10. Ratto C, Litta F, Parello A, et al. Gore Bio-A® Fistula Plug: a new sphincter-sparing procedure for complex anal fistula. Colorectal Dis 2012;14:e264-9.

11. Pigot F. Treatment of anal fistula and abscess. J Visc Surg 2015;152:S23-9.

12. Yusof S, Zhao Y. Novel use of video-assisted anal fistula treatment (VAAFT) fistuloscope in the treatment of chronic sinus tracts following low anterior resection. Asian

Cite this article as: Lei C, Li C, Liu M, Song Z, Li C, Liu Z. Proximal anal sinus resection as an alternative to fistulectomy and seton for reducing recurrence of anal fistulas: a retrospective study. Ann Palliat Med 2021;10(12):12273-12279. doi: 10.21037/apm-21-3127
J Surg 2020;43:851-2.

13. Emile SH, Elfeki H, Thabet W, et al. Predictive factors for recurrence of high transsphincteric anal fistula after placement of seton. J Surg Res 2017;213:261-8.

14. Romaniszyn M, Walega PJ, Nowak W. Efficacy of lift (ligation of intersphincteric fistula tract) for complex and recurrent anal fistulas--a single-center experience and a review of the literature. Pol Przegl Chir 2015;86:532-6.

15. Garcia-Olmo D, Guadalajara H, Rubio-Perez I, et al. Recurrent anal fistulae: limited surgery supported by stem cells. World J Gastroenterol 2015;21:3330-6.

16. Sica GS, Di Carlo S, Tema G, et al. Treatment of perianal fistula in Crohn's disease. World J Gastroenterol 2014;20:13205-10.

17. Gewali MB, Pilapitiya U, Hattori M, et al. Analysis of a thread used in the Kshara Sutra treatment in the Ayurvedic medicinal system. J Ethnopharmacol 1990;29:199-206. 